\title{
Semissimbolismo e as Categorias Tensivas Subjacentes
}

Carolina Lindenberg Lemos ${ }^{a}$

\section{Resumo}

Por meio da análise prática de um objeto sincrético - o livro infantil Chapeuzinho Amarelo, de Chico Buarque, com seu texto verbal e suas ilustrações -, buscamos abordar as formas de apreensão das relações entre o plano da expressão e o do conteúdo. Para tanto, discutimos os limites do semissimbolismo: estratégia de análise que busca homologações entre categorias dos dois planos. Em especial, o caráter contingente do semissimbolismo, que se refaz a cada nova análise, o torna de difícil generalização. Propusemos assim uma transposição das categorias semissimbólicas para as categorias da semiótica tensiva. Com isso, mostramos de que maneira as categorias tensivas organizam o desenrolar global do texto - tanto na expressão quanto no conteúdo -, como também sugerimos a sua expansão para a descrição de textos sincréticos em geral.

Palavras-chave: sincretismo, categorias tensivas, semissimbolismo 
O signo linguístico é, pois, uma entidade psíquica de duas faces [...]

Esses dois elementos estão intimamente unidos e um reclama o outro.

Ferdinand de Saussure

As ciências da linguagem atualmente têm buscado uma compreensão ampla da linguagem, entendida como faculdade cognitiva, isto é, integrando aspectos como a percepção, o raciocínio e as representações de formas sincréticas (de mais de uma dimensão expressiva). Esse é precisamente o cenário teórico em que se desenvolveu a semiótica desde Hjelmslev, ao postular o estudo das associações entre expressão e conteúdo, aplicáveis de maneira universal a qualquer tipo de sistema de significação.

Este trabalho insere-se no quadro teórico da semiótica de linha francesa e, em particular, segue os desenvolvimentos da semiótica tensiva. Em meio aos estudos de objetos sincréticos, abordaremos as relações que podem ser estabelecidas entre a expressão e o conteúdo desses textos. É por esse viés que procuramos, por meio de uma análise, trazer outra luz aos estudos de semiótica sincrética. Procuraremos abordar, assim, as relações tensivas que podem estar por trás das categorias semissimbólicas ou, de maneira geral, que podem estar na base da ligação entre expressão e conteúdo do texto sincrético aqui sob análise.

O objetivo geral desta investigação abarca a perspectiva de que a abordagem tensiva possa trazer um novo tratamento a questões já consagradas no campo da semiótica, nesse caso, à relação entre expressão e conteúdo. Como objetivos específicos, compararemos os elementos verbais e visuais de um livro infantil, com o intuito de explicar (i) de que forma a tensividade está presente nas categorias semissimbólicas; e (ii) como se pode partir diretamente de figuras da expressão e do conteúdo para a análise tensiva, sem que seja necessário fazer uso das categorias semissimbólicas.

\section{Definição de Sincretismo}

O sincretismo é um mecanismo que pode ser observado na homologação de dois elementos do plano da expressão (ou de elementos de dois planos da expressão de substâncias 
1 As definições de sincretismo apresentadas por Hjelmslev (2003, p. 93-97) e no primeiro tomo do dicionário de semiótica (GREIMAS; COURTÉS, 1993, p. 374375) são mais extensas. Hjelmslev (2003, p. 93) menciona inclusive que o sincretismo pode ser verificado tanto no plano da expressão quanto no plano do conteúdo.

2 Tradução nossa para: "On affirme ainsi la nécessité - et la possibilité - d'aborder ces objets comme des touts de signification et de procéder, dans un premier temps, à l'analyse de leur plan du contenu."

3 Tradução nossa para: "C'est en fonction d'un savoir acquis sur les différents degrés de correspondance et de coextensivité entre ces unités textuelles et les syntagmes narratifs, qu'on pourra revenir sur la manifestation et mieux comprendre les règles de sa distribution sur plusieurs langages, ainsi que les rôles et les statuts qui sont attribués à ces derniers; et que l'on pourra aborder le plan de l'expression." distintas - verbal e musical, verbal e visual, etc.) que geram a impressão de uma homogeneização do plano do conteúdo. Em outras palavras, as diferenças entre dois elementos do plano da expressão justapostos ou sobrepostos são suspensas e ambos parecem transmitir um mesmo sentido. ${ }^{1}$ Na semiótica, o sincretismo tomou outras conotações que, de certa forma, se afastam da definição original de Louis Hjelmslev. A semiótica greimasiana tratará de sincretismo de atores e actantes mecanismo exclusivamente do plano do conteúdo - e, por um alargamento do termo, de semióticas sincréticas: "Num sentido mais amplo, serão consideradas como sincréticas as semióticas que - como a ópera e o cinema - colocam em funcionamento diversas linguagens de manifestação." (GREIMAS; COURTÉS, 2011, p. 467).

Nesses termos, encontraremos vislumbrada já no segundo tomo do dicionário de semiótica (GREIMAS; COURTÉS, 1986) a possibilidade de analisar os objetos sincréticos de forma unitária: "Afirmamos assim a necessidade - e a possibilidade de abordar esses objetos [sincréticos] como todos de significação e de proceder, num primeiro momento, à análise de seu plano do conteúdo" (FLOCH, 1986, p. 218 - grifos nossos). ${ }^{2}$

A proposta levantada no trecho citado era a de, uma vez que os objetos sincréticos formavam um todo de significação, passar diretamente para a análise do conteúdo. Desde então, a semiótica tem desenvolvido ferramentas para descrever também o plano da expressão e suas relações com o plano do conteúdo, como também para relacionar os diferentes planos da expressão de uma obra sincrética, como já anunciava o mesmo verbete do Dicionário II:

É em função de um saber adquirido sobre os diferentes graus de correspondência e coextensividade entre essas unidades textuais e os sintagmas narrativos que se poderá retornar à manifestação e compreender melhor as regras de sua distribuição nas diferentes linguagens, bem como os papéis e estatutos que são atribuídos a estes últimos; e que se poderá abordar o plano da expressão. (FLOCH, 1986, p. 218) ${ }^{3}$

Nesses termos, podemos dizer que neste trabalho não se trata de redefinir ou problematizar o sincretismo. Vamos, ao contrário, supor que os avanços dos estudos acerca do plano do conteúdo nos fornece as bases mínimas para a abordagem do plano da expressão de um objeto sincrético. Em particular, 
escolhemos um livro infantil e consideraremos, com Floch, que o plano de conteúdo do livro é único, ainda que seu plano de expressão compreenda uma dimensão verbal e outra visual. Apresentaremos mais detidamente o objeto no item 3 abaixo. Entretanto, podemos já afirmar que, segundo o ponto de vista aqui adotado, a edição escolhida (BUARQUE, 1987) é um objeto fundamentalmente diferente de uma edição posterior do livro que adotou imagens de outro ilustrador (BUARQUE, 2003). As relações que serão exploradas aqui não se sustentam nessa outra versão e algo do conjunto se perde, não apenas na interpretação das imagens, mas sobretudo em sua relação com o texto. Usaremos, assim, esse objeto sincrético para desenvolver nossas investigações acerca das relações entre expressão e conteúdo. A escolha de uma semiótica sincrética se justifica na medida em que esse tipo de objeto traz questões para o semissimbolismo, como veremos.

\section{Acerca do Semissimbolismo}

Um dos mecanismos desenvolvidos pela semiótica para a análise dos textos sincréticos, talvez o mais difundido, é o semissimbolismo (GREIMAS; COURTÉS, 1986, p. 203 e 204.). Na prática, isso representa a busca de correlações entre categorias relevantes do plano da expressão e do plano do conteúdo, dessa forma contemplando mais detidamente os discursos poéticos e não-verbais. O mecanismo está ilustrado no conhecido exemplo do discurso gestual em que se usa o movimento vertical de cabeça para afirmar e o movimento horizontal para negar (GREIMAS; COURTÉS, 1986, p. 204). Assim, teríamos a seguinte relação:

verticalidade : horizontalidade : : afirmação : negação

A partir do exemplo citado, é possível notar que não há nenhuma relação necessária entre essas duas categorias. Trata-se de uma relação que se cria nesse contexto (do discurso gestual cotidiano) e se dissolve fora dele. Nada impede que num outro discurso a verticalidade esteja associada à negação, ou a um outro valor qualquer.

As relações semissimbólicas são necessariamente transitórias. No limite, isso se dá por força do imperativo 
saussuriano da arbitrariedade do signo (SAUSSURE, 1997, p. 81-84). Uma expressão não tem conteúdo, ela ganha conteúdo quando se faz signo. O "efeito semissimbólico" de que uma categoria independente do conteúdo corresponde necessariamente a uma categoria da expressão parece desafiar a arbitrariedade do signo: parece contraditório procurar motivação na relação entre significante e significado. Precisamos, no entanto, lançar mão de mais uma dicotomia saussuriana para justificar o semissimbolismo nesse quadro teórico. É preciso também considerar a oposição língua e fala, mais tarde reexaminada por Émile Benveniste (1995, p. 284-293) no quadro de uma oposição entre língua e discurso.

Como lembra o linguista francês (BENVENISTE, 1995, p. 54-59), a relação significado/significante é arbitrária por ser imotivada, mas, uma vez estabelecida culturalmente, essa relação passa a ser necessária. O que o semissimbolismo vai produzir é uma desconstrução dessa relação que se tornou necessária dentro de um dado sistema e incutir novos sentidos à categoria selecionada, criando a ilusão de que uma nova relação entre expressão e conteúdo gerada num texto é motivada - que aquela expressão deve necessariamente estar associada àquele conteúdo.

A relação semissimbólica é, como se disse, transitória. Essa característica preserva o princípio de arbitrariedade de Saussure. A ligação entre categorias terá sido função de uma escolha feita no discurso, na contingência do texto, e não altera definitivamente o sistema. ${ }^{4}$ Quando falamos de uma escolha no nível do discurso, sugerimos a presença de uma intencionalidade, da presença de um sujeito da enunciação (BENVENISTE, 2006, p. 82; GREIMAS; COURTÉS, 2011, p. 26-267). De fato, é em ato que a enunciação manipula os elementos da expressão para torná-los (re)significantes, ou seja, para injetar, no texto, novos sentidos ou reiterar os sentidos apreendidos no conteúdo. Nos termos de Louis Hjelmslev (2003, p. 121-125), cria-se uma semiótica conotativa.

Em Petites mythologies de l'oeil et de l'esprit, Jean-Marie sitória pode se tornar permanente se a nova relação semissimbólica for repetida suficientemente para que entre no sistema da língua. Veremos em mais detalhes abaixo. 
semissimbólicos, em que há conformidade entre os planos da expressão e do conteúdo, mas essa conformidade se dá entre categorias e não mais de termo a termo. A partir dessa divisão, Diana L. P. de Barros (2008, p. 29-31) vai especificar as aproximações e diferenças entre sistemas simbólicos e semissimbólicos. Em especial, a autora argumenta que os sistemas simbólicos são culturalmente determinados, enquanto os sistemas semissimbólicos vão pôr em xeque as relações fixadas pela cultura e reconstruir uma nova verdade a partir do interior do texto e criar outras formas de conhecer e sentir o mundo. Em seguida, a autora chama a atenção para o caráter gradual que existe entre os sistemas simbólicos e semissimbólicos, explicando que as relações semissimbólicas criam inovações, mas a repetição frequente de estratégias semissimbólicas pode levar a uma fixação cultural, de tal forma que aquilo que era antes visto como inovação passa então a ser visto como banal, como uma relação já esperada (BARROS, 2008, p. 34-37). Inversamente, podemos também supor que novos semissimbolismos podem não apenas se servir daquilo que é culturalmente determinado para reconstruí-lo, mas também guardar uma proximidade com as determinações culturais, permitindo-nos reconhecer a novidade ao mesmo tempo em que vemos preservada a relação cultural.

\section{O Semissimbolismo da Chapeuzinho}

Um exemplo de análise pode esclarecer este último ponto. Tomemos o livro Chapeuzinho Amarelo de Chico Buarque (1987), especialmente em sua relação com as ilustrações de Donatella Berlendis que fazem parte das primeiras edições. ${ }^{5}$

O livro é uma paródia de Chapeuzinho Vermelho. Nessa nova versão, Chapeuzinho Amarelo vai vencer certos medos, até mesmo do lobo, e seu amadurecimento vai se revelar na

5 Uma análise desse livro está publicada na revista eletrônica CASA (LINDENBERG LEMOS, 2008). Retomamos o objeto para lhe conferir uma nova abordagem e discutir a passagem às categorias tensivas. O que é apresentado aqui é, portanto, essencialmente novo. possibilidade de sair de casa e brincar - há, portanto, uma inversão da história original, em que Chapeuzinho Vermelho aprendera a ter medo do lobo (DISCINI, 2004, p. 180-181). As ilustrações do livro Chapeuzinho Amarelo são feitas por contorno pretos finos sobre fundo, em geral, branco. Os traços que fazem os olhos da menina são o elemento de destaque pela intensidade do traço mais espesso. Em sua maioria, as ilustrações comportam uma outra cor além do preto do 
contorno, como na segunda ilustração do livro ${ }^{6}$ (figura 1.1 abaixo). Vemos Chapeuzinho Amarelo em branco e preto, com as bochechas amareladas e uma expressão amedrontada.

Figura 1.1 - Bochechas Amarelas

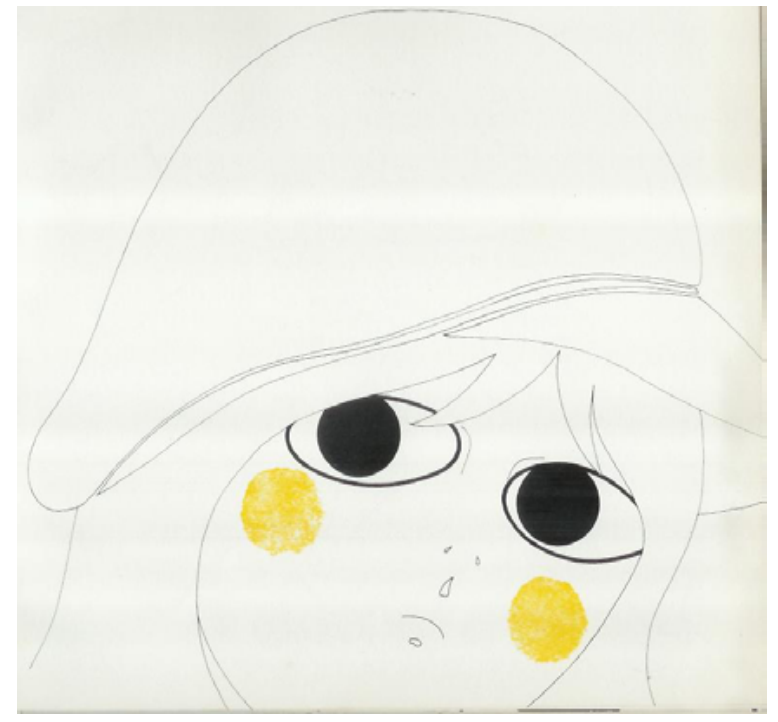

Conforme discutido em Lindenberg Lemos (2008), a cor amarela do desenho está associada ao estado doentio e amedrontado da menina no plano visual, bem como no plano verbal ("Amarelada de medo [...] Não estava resfriada /mas tossia"). Como sugere Diana Barros, essa associação está ancorada no conhecimento de mundo do leitor por meio da relação que essa cor estabelece, em português, com certos estados físicos e psíquicos em doenças como o "amarelão" e a hepatite, e em expressões do medo como "amarelou" ("desistiu porque teve medo"). É dessa forma que o semissimbolismo retira figuras do estabelecimento cultural para formar os termos de suas categorias.

Nesses termos, o uso do amarelo como figura do estado

6 A primeira ilustração é o desenho de um chapéu de aba amarela na página de rosto. de alma de Chapeuzinho Amarelo é feito tanto no texto verbal quanto no pictórico. Entretanto, é apenas nas ilustrações que uma nova cor se adiciona e percebemos uma passagem gradual do amarelo (por vezes no rosto, em outras no chapéu da menina) para o vermelho (no bolo, na maçã e, finalmente, no rosto de Chapeuzinho), como nas figuras 1.2 e 1.3: 
Figura 1.2 - Bolo Vermelho

LO-

Figura 1.3 - Bochechas Vermelhas

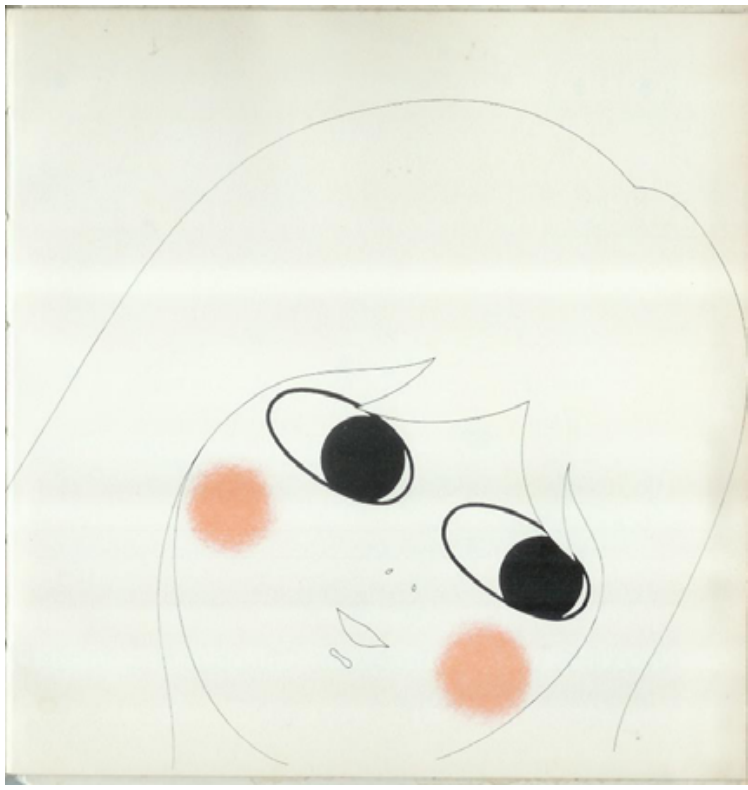

A estratégia de passagem do amarelo ao vermelho se dá exclusivamente no plano visual. As imagens acompanham e refletem a narrativa de conquista do medo, mas o texto verbal limita-se a evitar a palavra amarelo: Chapeuzinho Amarelo será apenas Chapeuzinho. Não há, contudo, referência à cor vermelha no plano escrito. Dessa forma, vemos, no início, a figura da menina de bochechas amarelas ao lado da descrição de seu estado amedrontado e doentio. O elemento vermelho começa a aparecer quando a menina dá sinais de que pode vencer seu medo. A resolução de seus temores é acompanhada de uma transformação física: as bochechas de Chapeuzinho passam de 
amarelo a vermelho (fig. 1.3 acima), quando ela se torna capaz de brincar, cair e levantar, e comer "de tudo, menos sola de sapato".

A combinação das cores e dos sentidos veiculados pelo texto nos permitiu propor um traço que chamaremos de "corporeidade" associado às cores (LINDENBERG LEMOS, 2008). Assim, há uma falta de corporeidade de um corpo mais doente ou debilitado na presença do amarelo, em oposição a uma forte corporeidade ligada ao vermelho, expressa no movimento, nas brincadeiras, nas novas atividades e no apetite da menina. Essa "corporeidade" é concebida de forma gradual: assim como temos uma maior concentração de cor na passagem do amarelo para o vermelho, temos uma intensificação correspondente na vivacidade da menina. Ao substituir o amarelo pelo vermelho, são substituídas a doença pelo apetite, a estaticidade pelo movimento (brincadeiras) e a horizontalidade (estar sempre deitada) pela verticalidade ("trepa em árvore", "cai, levanta..."). O jogo de cores das ilustrações colabora, portanto, para reforçar o tema da transformação pelo amadurecimento.

Na análise do livro infantil, pudemos identificar o exemplo de uma categoria da expressão - escala de cor: vermelho vs. amarelo - homologada a uma categoria do conteúdo, que, nesse caso, escolhemos chamar de "corporeidade", a fim de abarcar as múltiplas figuras do estado de saúde da menina: estaticidade vs. mobilidade, doença vs. saúde, horizontalidade $v s$. verticalidade (todas oposições do conteúdo, nesse caso). Entretanto, o ponto que buscávamos levantar é o de que, apesar de a cor amarela ser emprestada de uma valoração social e de ela ser ressignificada nas novas oposições que se criam no texto, a cor em si não deixa de guardar sua conotação social convocada a todo tempo no texto. É nesse sentido, também, que o semissimbolismo pode estar colocado num meio de caminho entre aquilo que é fixado culturalmente e o que é francamente inovador.

\section{Passagem às Categorias Tensivas}

Apesar da grande versatilidade que traz o semissimbolismo, as relações encontradas acabam por se revelar pouco justificadas na economia geral da análise do texto, pois são por demais acidentais e faltam elementos teóricos constantes que possam revelar o papel que essas categorias desempenham e como se ligam no interior do texto. Em outras 
palavras, é possível supor categorias mais abstratas, comuns à expressão e ao conteúdo, que se convertam em instrumental teórico e descritivo homogêneo para a análise de ambos os planos (TATIT, 2007, p. 18). Os sentidos incrementados pelo mecanismo semissimbólico podem atuar na economia geral do texto (BARROS, 2008, p. 33) e, portanto, pedem critérios de abordagem mais abrangentes.

Paralelamente aos desenvolvimentos da chamada teoria semiótica "padrão", surgiu, a partir da década de 1980, uma vertente que trazia propostas de desdobramentos do modelo, em especial para o nível fundamental: trata-se da semiótica tensiva, inicialmente proposta por Claude Zilberberg com adesão posterior de Jacques Fontanille e de outros semioticistas. Os instrumentos propostos por essa linha trazem novas maneiras de relacionar entre si as categorias encontradas no plano da expressão e no plano do conteúdo. As categorias tensivas são bastante abstratas e vão justamente "temporalizar" as categorias semissimbólicas, ou seja, vão tratar esses opostos não mais como categóricos, mas antes como elementos de um termo complexo, ou seja, dois elementos num contínuo do plano da expressão ou do conteúdo (TATIT, 2007, p. 28-38). Assim, a tensividade relaciona expressão e conteúdo "num patamar mais afastado da substância" (BARROS, 2008, p. 31).

Claude Zilberberg propõe relações extensas e intensas, fazeres emissivos e remissivos, espaços abertos e fechados num nível figural mais abstrato que os esquemas figurativos do nível discursivo (ZILBERBERG, 2006, p. 129-147). O interesse dessas categorias tensivas é que, justamente por serem tão abstratas, não estão necessariamente ligadas ao conteúdo, como as categorias da semiótica padrão sempre estiveram. Na realidade, elas retomam critérios sonoros, acentuais e dinâmicos, normalmente associados ao significante linguístico, abandonados pelos primeiros estudos semióticos. É o caso, por exemplo, da subvalência "musical" do andamento que nos permite verificar os movimentos de aceleração e desaceleração do texto (TATIT, 2007, p. 33-34). É por essa característica generalizante que as categorias tensivas se revelam tão adequadas a estabelecer a ligação entre expressão e conteúdo, a mesma que se reconhece no semissimbolismo. Se discutíamos que a diferença entre um sistema simbólico e um sistema semissimbólico é a de 
que naquele há uma relação termo a termo entre a expressão e o conteúdo, enquanto neste a relação se dá entre categorias, talvez seja plausível dizer que a semiótica tensiva oferece o termo complexo que subsume a categoria da expressão e a do conteúdo. Explicaremos no exemplo.

Se voltarmos às observações que fazíamos acerca de Chapeuzinho Amarelo, tínhamos as cores do lado da expressão e o estado de saúde da menina do lado do conteúdo:

amarelo : vermelho :: apatia : vivacidade

Dissemos que há, de um dos lados, uma relação entre os termos que associa a cor amarela ao estado de apatia, o que remete ao intertexto num sentido largo, nos valores fixados pelos incontáveis textos que formam uma cultura. Entretanto, no arranjo do texto, parece haver uma categoria mais geral que liga amarelo e apatia de um lado, vermelho e vivacidade de outro; uma espécie de "motivação" interna, uma qualidade que está presente tanto nas cores quanto no estado da garota. Quando doente, parece faltar a Chapeuzinho intensidade ou, mais particularmente, tonicidade: um querer forte, ao invés de uma renúncia. Se, por outro lado, observarmos as cores escolhidas, veremos que a distância entre o vermelho e o amarelo também pode ser entendida como uma diferença de tonicidade, se considerarmos que a cor vermelha é mais tônica que o amarelo nesse contexto. Assim, na expressão como no conteúdo, temos o recrudescimento da subdimensão da tonicidade, que é o traço comum que nos faz entender a seleção feita nesse texto: amarelo, na mesma cultura a que está ligado esse livro, também pode simbolizar vida e calor, por meio de figuras como o sol, o mel, por exemplo. No entanto, pela ligação fundamental que se estabelece com o estado de alma da menina, pela sobredeterminação tensiva que as figuras dos dois planos da linguagem recebem, sabemos não ser eufórica a valoração dessa cor. "Amarelo" e "apatia" ocupam, cada um em seu plano, o mesmo lugar na economia geral do texto. A tonicidade, nesse exemplo, é o termo complexo que promove a ligação entre expressão e conteúdo. É a categoria complexa que faz perceber que dois termos são comparáveis, ou seja, que estão em tensão (TATIT, 2007, p. 40 e 49). 
Da mesma forma como partimos, nesse exemplo que vimos desenvolvendo, de uma série de figuras do conteúdo que se ligam à categoria expressiva: estaticidade vs. mobilidade, doença vs. saúde, horizontalidade vs. verticalidade e que dessas oposições chegamos a uma oposição mais geral como apatia vs. vivacidade para estabelecer a categoria do conteúdo que entra na relação semissimbólica, podemos também pensar que, se já contamos com a categoria tensiva abstrata que forma o nível figural, talvez não seja necessário que toda análise passe pela etapa de constituição dessa categoria intermediária. É possível imaginar um transporte direto das figuras da expressão e do conteúdo para as categorias tensivas. Um argumento nesse sentido é a constatação de que das palavras em estado de dicionário já podemos apreender uma dimensão tensiva. Para exemplos nesse sentido, podemos conferir o trabalho de Zilberberg (2008, p. 5-15) sobre os diferentes tons de rosa. A partir de um procedimento já difundido na semiótica, o autor procede a uma consulta a diversos dicionários da língua francesa para tomá-los como representantes do que está consagrado naquela cultura, seguindo daí para uma análise das tonicidades e temporalidades dos vários tons da cor rosa.

Por outro lado, a semiótica tensiva propõe uma forma de interação entre as dimensões e subdimensões de seu aparato metodológico (ZILBERBERG, 2007, p. 3-13), uma vez que ela determina os efeitos que cada subdimensão da intensidade tem sobre as subdimensões da extensidade e chega a dizer que a dimensão da intensidade "rege" a extensidade, afirmação que ainda está por ser desenvolvida. Dessa forma, mesmo que uma dada categoria da expressão diga respeito a uma subdimensão e a categoria do conteúdo a uma outra, é possível prever e analisar a interação dessas categorias de dentro do esquematismo tensivo. Essa perspectiva permanecerá, entretanto, como hipótese para explorações futuras. ${ }^{7}$

A partir dessa discussão, voltamos à proposta de investigação apresentada acima. Somamos às propostas iniciais a observação de que as relações semissimbólicas entre

7 Para exemplos de uma interação mais complexa das categorias tensivas na análise dos dois planos, ver Lindenberg Lemos (2010). expressão e conteúdo não atingem apenas localmente o texto, mas podem entrar no cômputo geral da cifra tensiva do texto. Como vimos no livro de Chico Buarque, a cifra atestada nos elementos de expressão e conteúdo regem todo o desenrolar 
da narrativa, que gira em torno de uma recuperação de uma corporeidade mais tônica: a possibilidade de vencer o medo e poder viver. Vimos ainda que a tensividade pode ser apreendida a partir das figuras do nível discursivo e das figuras da expressão, sem necessariamente passar por categorias intermediárias ou por todas as etapas do percurso gerativo do sentido. Assim, o recurso a categorias tensivas trouxe um grau de generalidade importante para a análise das interações entre expressão e conteúdo, fazendo o modelo mais facilmente replicável e, dessa forma, mais robusto.

\section{REFERÊNCIAS}

BARROS, D. L. P. “Semiótica e retórica: um diálogo produtivo." In: LARA, G. M. P. et al. (eds.). Análises do Discurso Hoje. Rio de Janeiro, Nova Fronteira / Lucerna, 2008, p. 27-39.

BENVENISTE, É. Problemas de Linguística Geral. Tomo I. Tradução de Maria da Glória Novak e Maria Luisa Neri. Campinas: Pontes / Editora da Unicamp, 1995.

. Problemas de Linguística Geral. Tomo II. Tradução de Eduardo Guimarães et al. Campinas: Pontes, 2006.

BUARQUE, C. Chapeuzinho Amarelo. Ilustrações de Donatella Berlendis. 10 a ed. São Paulo, Berlendis e Vertecchia, 1987.

Chapeuzinho Amarelo. Ilustrações de Ziraldo. 13 ed. Rio de Janeiro, José Olympio, 2003.

DISCINI, N. Intertextualidade e o Conto Maravilhoso. São Paulo, Humanitas, 2004.

FLOCH, J.-M. Petites mythologies de l'oeil et de l'esprit: pour une sémiotique plastique. Paris / Amsterdã, Hadès / Benjamins, 1985.

FONTANILLE, J. "Affichages: de la sémiotique des objets à la sémiotique des situation." Nouveaux Actes Sémiotiques, v. 1, 2004. Disponível em: $<$ http://revues.unilim.fr/nas/document. php?id=1487>. 
GREIMAS, A. J.; COURTÉS, J. (eds.). Sémiotique: dictionnaire raisonné de la théorie du langage. Tomo II. Paris, Hachette, 1986. Sémiotique: dictionnaire raisonné de la théorie du langage. Tomo I. Paris, Hachette, 1993.

HJELMSLEV, L. Prolegômenos a uma Teoria da Linguagem. Tradução de J. Teixeira Coelho Netto. São Paulo, Perspectiva, 2003.

LINDENBERG LEMOS, C. “Um chapéu amarelo e um capuz vermelho: uma leitura semiótica de Chapeuzinho Amarelo de Chico Buarque." CASA - Cadernos de Semiótica Aplicada, v. 6, n. 1, 2008. Disponível em: <http://www.fclar.unesp.br/seer/ index.php?journal $=$ casa $>$.

Entre Expressões e Conteúdos: do Semissimbolismo às Categorias Tensivas. $122 \mathrm{f}$. Dissertação (Mestrado em Linguística). Universidade de São Paulo, São Paulo, 2010. Disponível em: <http://www.teses.usp.br/teses/ disponiveis/8/8139/tde-30042010-121008/publico/ CAROLINA_LINDENBERG_LEMOS.pdf $>$.

SAUSSURE, F. Curso de Linguística Geral. Tradução de Antônio Chelini, José Paulo Paes e Izidoro Blikstein. São Paulo, Cultrix, 1997.

TATIT, L. Hjelmslev e as Bases Tensivas do Semi-simbolismo. São Paulo: Editora do CPS, 2007.

ZILBERBERG, C. Razãoe Poética do Sentido. Tradução de Ivã Carlos Lopes, Luiz Tatit e Waldir Beividas. São Paulo: Edusp, 2006.

. "De la consistance". Inédito. Saint Maur, França, 2007. Disponível em: <http://www.claudezilberberg.net/pdfs/ De\%20la\%20consistance.pdf $>$.

. "Causerie sur la sémiotique tensive". Inédito. Saint Maur, França, 2008. Disponível em: <http://www.fflch. usp.br/dl/semiotica/cursos/zilberberg2008/cz-causerie.pdf>. 


\section{Abstract}

\section{Semi-symbolism and the Underlying Tensive Categories}

Through a practical analysis of a syncretic object the children's book Chapeuzinho Amarelo, by Chico Buarque, with its verbal and pictorial components -, we have investigated different forms of apprehending the relations between the expression plane and the content plane. To do so, we discuss the limits of semi-symbolism: an analytical strategy that searches for parallelisms between categories of both planes. Most importantly, the contingent characteristic of semi-symbolism, which must be reconstructed at each analysis, makes all attempts at generalization difficult. We proposed thus a transposition of semisymbolic categories onto those from tensive semiotics. We therefore showed how tensive categories - in both expression and content - organize the text globally, also suggesting its expansion to the description of syncretic texts in general.

Keywords: syncretism, tensive categories, semisymbolism. 